\title{
Células solares sensibilizadas com corantes naturais extraído das plantas Nerium oleander e Portulaca grandiflora
}

\section{Dye-sensitized solar cell using natural dyes extracted from Nerium oleander plants and Portulaca grandiflora}

\author{
Alexandra de Vasconcelos Feitosa, José Hugo de Aguiar Sousa² e \\ Francisco Sales Ávila Cavalcante ${ }^{1}$ \\ alexandravf@bol.com.br; profhugoaguiar@gmail.com; sales.avila@uece.br \\ ${ }^{1}$ Universidade Federal do Ceará, CE, Brasil \\ ${ }^{2}$ Universidade Estadual do Ceará, CE, Brasil
}

\begin{abstract}
Resumo
A utilização da energia solar para geração da energia elétrica tem sido cada vez mais considerada em vários países do mundo como uma ótima alternativa para redução dos impactos ambientais causados pelo homem, especialmente os associados às mudanças climáticas. Células solares sensibilizadas por corante têm sido estudadas como uma promissora fonte de energia renovável, devido à sua tecnologia de fabricação de baixo custo em comparação com células solares de silício. Neste trabalho, os sensibilizadores utilizados foram corantes naturais extraídos de pétalas de duas plantas ornamentais encontradas no Brasil: Nerium oleander $e$ Portulaca grandiflora. Os resultados mostram que os solventes absorvem na região do visível e o melhor resultado foi obtido utilizando o extrato etanólico da planta Nerium oleander com densidade de corrente de $0,24 \mathrm{~mA} / \mathrm{cm}^{2}$.
\end{abstract}

Palavras-chave: Corante natural, Células solares, Energia solar.

\begin{abstract}
The utilization of solar energy to generate electric power has been considered in worldwide as an optimal alternative to reduce the environment impacts caused by the mankind, mainly that associated to the climate change. Dye sensitized solar cells have been studied as a promising source of renewable energy due to low cost manufacturing technology in comparison with silicon solar cells. In this work, the sensitizers used were natural dyes extracted from two ornamental petals plants found in Brazil: Nerium oleander and Portulaca grandiflora. The results show that the solvents absorb in the visible region and the best result was obtained using ethanolic extract of Nerium oleander plant with current density of $0.24 \mathrm{~mA} / \mathrm{cm}^{2}$.
\end{abstract}

Keywords: Natural dye, Solar cells, Solar energy. 


\section{Introdução}

Células solares sensibilizadas por corante (Dye Sensitized Solar Cell - DSSC) têm sido estudadas na última década como uma promissora fonte de energia renovável, devido à sua tecnologia de fabricação de baixo custo em comparação com células solares de silício (O'REGAN; GR ÄTZEL, 1991; GRÄTZEL, 2001).

As DSSC são constituídas por um eletrodo formado por um material semicondutor $\left(\mathrm{TiO}_{2}\right)$ depositado num substrato condutor composto por dióxido de estanho $\left(\mathrm{SnO}_{2}\right)$, corante sensibilizador, eletrólito contendo o par redox iodeto/triiodeto que preenche o óxido poroso. $\mathrm{O}$ dispositivo é fechado com um contra-eletrodo formado de um material catalítico (TOBIN et al., 2011; GRÄTZEL, 2004; KALYANASUNDARAM; GRÄTZEL, 1998; GRÄTZEL, 2003; O’REGAN; GRÄTZEL, 1991).

Quando a célula solar fotoeletroquímica é irradiada com luz visível, moléculas do corante absorvem essa radiação e passam a um estado excitado. Essas moléculas excitadas injetam elétrons na banda de condução do semicondutor $\mathrm{TiO}_{2}$, ficando num estado oxidado. Esses elétrons são transportados para o contra-eletrodo, via circuito externo, e então, injetados no eletrólito, onde reagem com o par oxi-redutor (iodeto/triodeto) e a seguir com a molécula que havia sido oxidada, completando o processo regenerativo da célula (GRÄTZEL, 2003).

O mais bem sucedido sensibilizador com transferência eletrônica fotoinduzidas empregada até agora nessas células são os complexos de polipiridínicos de rutênio (II) com ligantes carboxilados com eficiência de conversão fotovoltaica global de aproximadamente 10\% (GR ÄTZEL, 2003).

Alternativamente, os corantes naturais podem ser utilizados com a mesma finalidade e com eficiência aceitável. A sensibilização de semicondutores com alto band gap usando pigmentos naturais é geralmente atribuída à presença de antocianinas (PATROCÍNIO et al., 2009; GÓMEZ-ORTÍZ et al., 2010; GARCIA et al., 2003; LUO et al., 2009; HAO et al., 2005)

As antocianinas absorvem na região do visível, por isso elas têm grande possibilidade de serem bons sensibilizadores para semicondutores com grande band gap (HAO et al., 2006; MAURYA et al., 2016), esta é uma característica importante que as tornam propícias para o uso nestas células.

As antocianinas estão presentes nas folhas, frutos e flores das plantas e podem ser facilmente obtidas por processos extrativos convencionais, o que torna mais barato o custo de produção da célula solar, comparandose àquelas em que são usados corantes sintéticos, tais como os complexos de rutênio (HAO et al., 2005). Além das antocianinas, outros pigmentos estão sendo estudados como os carotenóides (YAMAZAKI et al., 2007; GÓMEZ -ORTÍZ et al., 2010), as betalaínas (ZHANG et al., 2008) e a clorofila (CHANG et al., 2010). No entanto, a eficiência do corante natural ainda é inferior ao corante sintético.

Grupos hidroxila e carbonila presentes na molécula de antocianina podem ligar-se à superfície de um filme poroso de $\mathrm{TiO}_{2}$ (LUO et al., 2009). Isso faz com que haja transferência de elétrons da molécula de antocianina para a banda de condução do $\mathrm{TiO}_{2}$ (HAO et al., 2005; POLO; IHA, 2006; LUO et al., 2009; GARCIA et al., 2003).

Neste trabalho foram preparadas células solares utilizando corante natural extraído das pétalas das plantas Nerium oleander e Portulaca grandiflora, conhecidas popularmente como espirradeira e onze-horas, respectivamente. O solvente extrator para preparação do corante foi variado e cada extrato foi analisado oticamente. Os corantes foram sensibilizados em substratos de $\mathrm{TiO}_{2}$ preparados pela técnica de silk screen e cada célula foi caracterizada eletricamente mediante o levantamento de curvas de corrente versus tensão.

\section{Materiais e métodos}

\section{Preparação do corante natural}

As pétalas das plantas Nerium oleander e Portulaca grandiflora foram pesadas e maceradas em três solventes distintos, utilizando a proporção de 1:4 (m/v). O material permaneceu em cada solvente por $24 \mathrm{~h}$ sob refrigeração $\left(5,0 \pm 1,0{ }^{\circ} \mathrm{C}\right)$. Em seguida, o material foi prensado e filtrado em funil comum contendo algodão para remover os resíduos.

Os solventes utilizados para a extração foram: etanol (PA), etanol acidificado com solução de ácido clorídrico $0,1 \mathrm{M}$ com $\mathrm{pH}=2$ e etanol acidificado com ácido acético $(\mathrm{pH}=3)$.

\section{Preparação do eletrodo de $\mathrm{TiO}_{2}$}

O filme poroso de $\mathrm{TiO}_{2}$ foi preparado em substrato de vidro condutor recobertos com película de $\mathrm{SnO}_{2}$ (resistência de $70 \Omega / \square$ ) pela técnica de silk screen. Os substratos foram previamente limpos utilizando os seguintes solventes: éter de petróleo, acetona e álcool isopropílico, respectivamente em ultrassom por $1 \mathrm{~min}$ em cada solvente. A pasta de $\mathrm{TiO}_{2}$ foi preparada utilizando 3,0 g pó de $\mathrm{TiO}_{2}$ (P-25 DEGUSSA), 0,2 g de etil celulose, $10 \mathrm{~mL}$ de etanol e $0,15 \mathrm{~mL}$ de triton $\mathrm{X}-100$. A dispersão foi ultrassonificada por $30 \mathrm{~min}$.

O processo de deposição consiste em colocar a pasta sobre tela serigráfica de poliéster, $35 \mathrm{~cm}$ x $25 \mathrm{~cm}$, contendo 165 fios por centímetro quadrado e com uma espátula é feito o preenchimento dos poros da mesma, sem fazer a impressão, e em seguida, a pasta é trazida com o rodo fazendo a impressão do desenho definido na tela.

Foram depositadas, manualmente, quatro camadas da solução pastosa de $\mathrm{TiO}_{2}$ sobre o substrato condutor de dimensões 2,6 cm x 2,0 cm. Após a deposição, os filmes foram sinterizados até $450{ }^{\circ} \mathrm{C}\left( \pm 7,0^{\circ} \mathrm{C}\right)$ e permanecendo nesta temperatura por $30 \mathrm{~min}$. Após a sinterização o filme foi imerso no corante que por $2 \mathrm{~h}$ e o excesso foi 
removido com água destilada e etanol.

\section{Montagem das células solares}

Os testes foram realizados em uma cuba de teflon composta por dois eletrodos de área ativa de $1,0 \mathrm{~cm}^{2}$. O eletrodo utilizado foi o filme de $\mathrm{TiO}_{2}$ adsorvido com o corante e o contra eletrodo utilizado foi uma chapa de platina.

Entre os dois eletrodos foi injetado o eletrólito líquido (1 M KI + 0,1 M I dissolvido em etileno glicol na proporção de 1:1), formando um dispositivo tipo sanduíche com a seguinte configuração:

Vidro-condutor $/ \mathrm{TiO}_{2}$-corante // $\mathrm{I}_{3}^{-} / \mathrm{I}^{-} / / \mathrm{Pt}$

\section{Medição e caracterização de eficiência e con- versão das células solares}

A caracterização ótica é feita na faixa do visível através da obtenção dos espectros de absorção ótica na região do visível utilizando o espectrofotômetro UV-Vis (Hewelett-Packard 8453 Diode-Array) e a caracterização fotoeletroquímica das células é obtida através de curvas de corrente versus tensão, onde são comparados os parâmetros de corrente de curto-circuito $\left(\mathrm{I}_{\mathrm{sc}}\right)$, potencial de circuito aberto $\left(\mathrm{V}_{\mathrm{oc}}\right)$, eficiência do dispositivo $(\eta)$, potência máxima $\left(\mathrm{P}_{\max }\right)$ e fator de forma $(\mathrm{FF})$.

As curvas de densidade de corrente $\left(\mathrm{J}_{\mathrm{sc}}\right)$ x potencial (V) foram obtidas utilizando potenciostato da Microquímica, sendo a célula iluminada com uma lâmpada de irradiação A.M 1.5, sob intensidade de $1000 \mathrm{~W} / \mathrm{m}^{2}$. Essas curvas fornecem informações importantes sobre o comportamento da célula fotoeletroquímica sob irradiação, assim como a determinação de sua qualidade e desempenho.

\section{Resultados e discussões}

\section{Espectroscopia de absorção}

As Figuras 1 e 2 apresentam os espectros de absorção dos extratos obtidos das pétalas das plantas Nerium oleander e Portulaca grandiflora na região do visível nos solventes etanol, etanol acidificado com ácido clorídrico e acético.

Os extratos da planta Nerium oleander apresentaram apenas um pico na região do visível. Os picos obtidos foram: $543 \mathrm{~nm}$ utilizando etanol, $539 \mathrm{~nm}$ com etanol e ácido acético e $537 \mathrm{~nm}$ com etanol acidificado com ácido clorídrico. O extrato obtido por essa planta é de coloração vinho que se intensifica com a redução do $\mathrm{pH}$.

Os extratos das pétalas da planta Portulaca grandiflora apresentaram picos em $443 \mathrm{~nm}, 473 \mathrm{~nm}, 537 \mathrm{~nm}$ e 664 $\mathrm{nm}$, utilizando o solvente etanol. Quando a extração foi feita etanol acidificado com ácido clorídrico e com ácido acético foi obtido apenas um pico na região do visível em $546 \mathrm{~nm}$ e $547 \mathrm{~nm}$, respectivamente. O extrato apresenta cor violeta que também se intensifica com a redução do $\mathrm{pH}$.

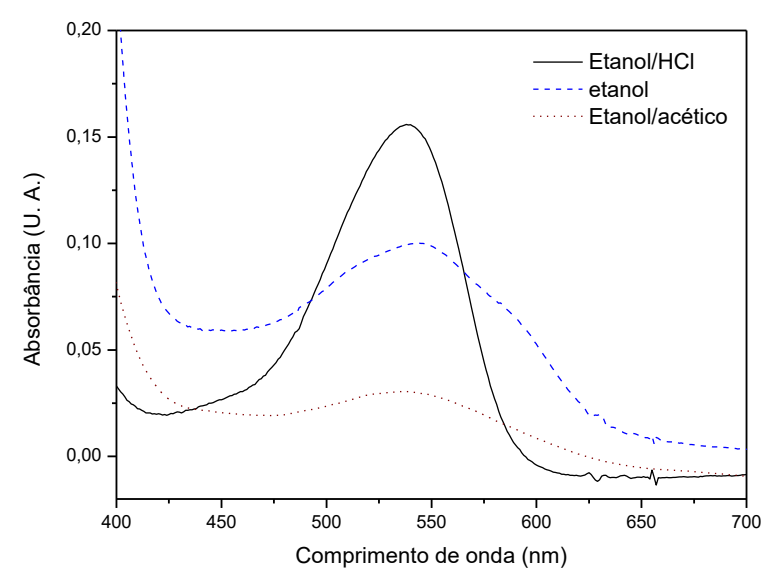

Figura 1 - Espectros de absorção dos corantes da planta Nerium oleander extraído com diferentes solventes: etanol, etanol/ $\mathrm{HCl}$ e etanol/ácido acético.

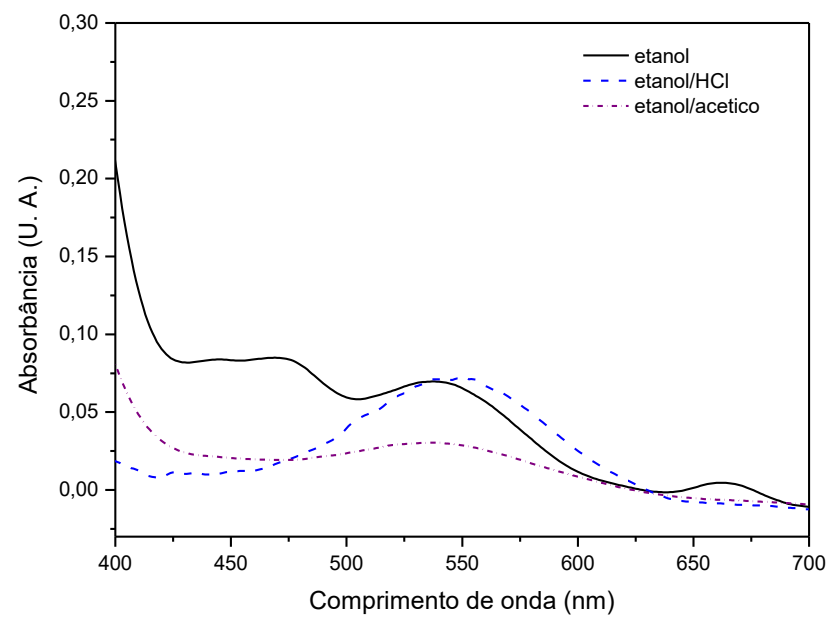

Figura 2 - Espectros de absorção dos corantes da planta Portulaca grandiflora extraído com diferentes solventes: etanol, etanol/ $\mathrm{HCl}$ e etanol/ácido acético.

A antocianina é o principal componente de alguns corantes naturais extraído de folhas, frutos e flores das plantas e, em geral, apresentam absorção máxima na faixa do visível (CALOGERO; DI MARCO, 2008). A posição dos picos e a sua intensidade variam de acordo com o solvente utilizado na extração e o pH do meio (REVILLA et al., 1998; KONG et al., 2003). Os picos apresentados na faixa entre 465 a $550 \mathrm{~nm}$ são característicos de antocianinas, o que mostra que os extratos naturais produzidos possuem tais substâncias.

As antocianinas apresentam uma ampla banda de transição de transferência de carga do orbital preenchido (HOMO) para orbital de baixa energia (LUMO) na região do visível (POLO; IHA, 2006). Por causa 
da absorção na região do visível do vermelho ao azul, elas são bastante promissoras para serem usadas como sensibilizadores em semicondutores com alto valor de band gap como o $\mathrm{TiO}_{2}(3,0 \mathrm{eV})$.

\section{Propriedades fotoeletroquímica das células}

\section{solares sensibilizadas com corante natural}

O desempenho dos corantes naturais sensibilizados foram avaliados em termos de corrente de curto circuito $\left(\mathrm{I}_{\mathrm{sc}}\right)$, potencial de circuito aberto $\left(\mathrm{V}_{\mathrm{oc}}\right)$, potência máxima $\left(\mathrm{P}_{\text {máx }}\right)$ e fator de forma (FF). As curvas de densidade de corrente $\left(\mathrm{J}_{\mathrm{sc}}\right)$ x potencial $(\mathrm{V})$ foram obtidas utilizando potenciostato (Microquímica), sendo a célula iluminada com uma lâmpada de irradiação A.M 1.5, sob intensidade de $1000 \mathrm{~W} / \mathrm{m}^{2}$.

A Figura 3 mostra a curva de célula para os extratos

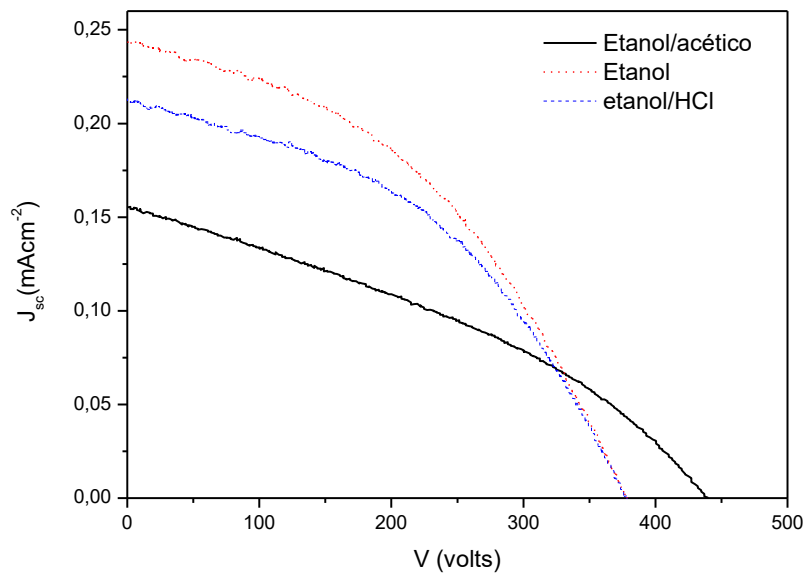

Figura 3 - Curva $\mathrm{J}_{\mathrm{sc}} \times \mathrm{V}$ de célula utilizando corante da planta Nerium oleander extraído com diferentes

da planta Nerium olander em diferentes solventes extratores. Enquanto que a Figura 4 apresenta as curvas
$\mathrm{J}_{\mathrm{sc}}$-V das células com os extratos da planta Portulaca grandiflora.

O extrato etanólico da planta Nerium olander apresentou densidade de corrente $0,24 \mathrm{mAcm}^{-2} \mathrm{e} \mathrm{V}_{\text {oc }}$ de 0,39 V. A potência máxima desse extrato foi calculada pela fórmula $P_{\max }=(I \times V)_{\text {Max }}$ e o resultado obtido foi de 0,04 $\mathrm{mWcm}^{-2}$. O fator de forma (FF) é calculado por $\mathrm{FF}=(\mathrm{Ix}$

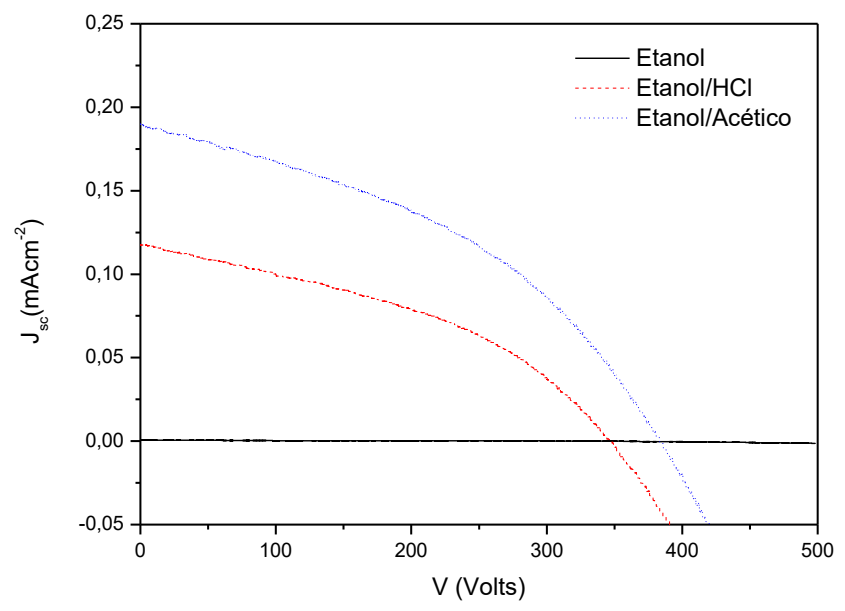

Figura 4 - Curva $\mathrm{J}_{\mathrm{sc}} \times \mathrm{V}$ de célula utilizando corante da planta Portulaca grandiflora extraído com diferentes solventes: etanol, etanol/ $\mathrm{HCl}$ e etanol/ácido acético.

$\mathrm{V})_{\mathrm{Max}} /\left(\mathrm{I}_{\mathrm{sc}} \times \mathrm{V}_{\mathrm{oc}}\right)$ e foi encontrado o valor de 0,42 . Com o extrato da planta Portulaca grandiflora o melhor extrato obtido foi utilizando o solvente etanol acidificado com ácido acético com densidade de corrente de 0,19 $\mathrm{mAcm}^{-2}, \mathrm{~V}_{\text {oc }}$ de $0,40 \mathrm{~V}$ e fator de forma (FF) de 0,40.

A Tabela 1 compara os diferentes parâmetros de DSSC usando diferentes solventes. Como apresentado na tabela, a densidade de corrente do extrato utilizando apenas etanol como solvente da planta Nerium olander é maior do que as demais densidades de corrente, obtida com os extratos etanólicos acidificados. Esse resultado é também

Tabela 1 - Parâmetros característicos dos dispositivos usando como corante a planta das plantas Nerium oleander e Portulaca grandiflora.

\begin{tabular}{|c|c|c|c|c|r|}
\hline \multirow{4}{*}{ Planta } & Solvente extrator & $\mathbf{J}_{\mathbf{s c}}\left(\mathbf{m} \mathbf{A c m} \mathbf{c m}^{-2}\right)$ & $\mathbf{V}_{\mathbf{o c}} \mathbf{( V )}$ & $\mathbf{P}_{\text {máx }}\left(\mathbf{m} \mathbf{W} \mathbf{c m}^{-2}\right)$ & FF \\
\hline \multirow{3}{*}{\begin{tabular}{c} 
Nerium oleander \\
\cline { 2 - 6 }
\end{tabular}} & $\begin{array}{c}\text { Etanol } \\
\text { clonídrico }\end{array}$ & 0,24 & 0,39 & 0,04 & 0,42 \\
\cline { 2 - 6 } & Etanol + ácido acético & 0,16 & 0,43 & 0,03 & 0,43 \\
\hline \multirow{3}{*}{$\begin{array}{c}\text { Portulaca } \\
\text { grandiflora }\end{array}$} & Etanol & 0,00 & 0,44 & 0,00 & 0,35 \\
\cline { 2 - 6 } & $\begin{array}{c}\text { Etanol + ácido } \\
\text { clorídrico }\end{array}$ & 0,12 & 0,35 & 0,02 & 0,40 \\
\cline { 2 - 6 } & Etanol + ácido acético & 0,19 & 0,38 & 0,03 & 0,40 \\
\hline
\end{tabular}


é superior quando comparado com os extratos da planta Portulaca grandiflora, isso ocorre porque deve haver uma maior interação entre as nanopartículas do semicondutor $\mathrm{TiO}_{2}$ e do pigmento fotosensibilizador do extrato etanólico da planta Nerium olander, onde o $\mathrm{TiO}_{2}$ é transparente para luz visível necessitando assim de luz ultra violeta para gerar pares elétrons-buracos. Com a adição do corante facilita-se esse processo onde o filme de corante absorve a luz na sua cor especifica. Assim o $\mathrm{TiO}_{2}$ e o corante possuem o mesmo nível de Fermi. Os elétrons que estão no nível de valência do corante e podem ser injetados para a banda de condução do $\mathrm{TiO}_{2}$. Surgindo assim, a formação de pares elétrons-buracos e a produção de eletricidade (AGNALDO et al., 2006).

Resultados similares de DSSC com densidade de corrente inferior a $0,5 \mathrm{mAcm}^{-2}$ foram encontrados na literatura quando se usa corante natural extraído das seguintes plantas que apresentam as respectivas densidades de corrente: pétalas da gardênia $-0,45 \mathrm{mAcm}^{-2}$ (ZHANG et al., 2008), 0,37 $\mathrm{mAcm}^{-2}$ utilizando o extrato da flor da ervilha azul (WONGCHAREE et al., 2007), 0,14 $\mathrm{mAcm}^{-2}$ quando se utiliza como sensibilizador pétalas da planta erva-das-sete-sangrias (Lithospermum) (ZHOU et al., 2011) e $0,22 \mathrm{mAcm}^{-2}$ quando se utiliza o extrato da pimenta vermelha como sensibilizador (HAO et al., 2011).

\section{Conclusão}

Os corantes naturais foram extraídos das plantas $\mathrm{Ne}$ rium oleander e Portulaca grandiflora nos solventes etanol, etanol acidificado com ácido clorídrico e ácido acético. Os resultados de UV-vis mostram que os extratos obtidos apresentam picos na região visível, sendo viável na utilização em DSSC. Entre os extratos obtidos e testados o melhor fotosensibilizador foi o extrato etanólico da planta Nerium oleander com densidade de corrente de $0,24 \mathrm{mAcm}^{-2}$ e da planta Portulaca grandiflora foi o extrato etanólico acidificado com ácido acético, apresentando densidade de corrente de $0,19 \mathrm{mAcm}^{-2}$. Verifica-se que o solvente modifica o extrato e consequentemente o modo de interagir com o óxido. De um modo geral, conclui-se que as células solares regenerativas mostram resultados promissores, sendo necessário aperfeiçoar as condições de preparação, com o intuito de melhorar o desempenho e a eficiência total do dispositivo.

\section{Agradecimentos}

Os autores agradecem a CAPES e a FUNCAP pelo apoio financeiro do projeto.

\section{Referências}

AGNALDO, J. S.; BASTOS, J. B. V.; CRESSONI, J. C.;
VISWANATHAN, G. M. Células solares de $\mathrm{TiO}_{2}$ sensibilizadas por corante. Revista Brasileira de Ensino de Física, v. 28, p. 77 - 84, 2006.

CALOGERO, G.; DI MARCO, G. Red Sicilian orange and purple eggplant fruits as natural sensitizers for dye-sensitized solar cells. Solar energy material \& solar cells, v. 92, p. 1341 -1346, 2008.

CHANG, H.; WU, H. M.; CHEN, T. L.; HUANG, K. D.; JWO, C. S.; LO, Y. J. Dye-sensitized solar cell using natural dyes extracted from spinach and ipomoea. Journal of Alloys and Compounds, v. 495, n. 2, p. 606-610, 2010.

GARCIA, C.G.; POLO, A. S.; IHA, N.Y.M. Fruit extracts and ruthenium polypyridinic dyes for sensitization of $\mathrm{TiO}_{2}$ in photoelectrochemical solar cells. J. photochem. photobiol. A: chem., v. 160, p. 8791, 2003.

GÓMEZ-ORTÍZ, N. M.; VÁZQUEZ-MALDONADO, I. A.; PÉREZ-ESPADAS, A. R.; MENA-REJÓN, G. J.; AZAMAR-BARRIOS, J. A.; OSKAM, G. Dyesensitized solar cells with natural dyes extracted from achiote seeds. Solar energy \& solar cells, v. 94, p. $40-44,2010$.

GRÄTZEL, M. Conversion of sunlight to eletric power by nanocrystaline dye-sensitized solar cells. J. Photochem. Photobiol. A: Chem., v. 164, p. 3-14, 2004.

GRÄTZEL, M. Dye-sensitized solar cells. J. Photochem. Photobiol. C: Photochem. Rev., v. 4, p. 145-153, 2003.

GRÄTZEL, M. Photoelectrochemical cells. Nature, v. 414, p. 338-344, 2001.

HAN, J.; CHEN, J. M.; ZHOU, X. W.; LIN, Y.; ZHANG, J. B.; JIA, J. G. Dye-sensitized solid-state solar cells fabricated by screen-printed $\mathrm{TiO}_{2}$ thin film with addition of polystyrene balls. Chinese Chemical Letters, v. 19, p. 1004-1007, 2008.

HAO, S.; WU, J.; HUANG, Y.; LIN, J. Natural dyes as photosensitizers for dye-sensitized solar cell. Solar Energy, v. 80, n. 2, p. 209-214, 2006.

ITO, S.; MURAKAMI, T. N.; COMTE, P.; LISKA, P.; GRÄTZEL, C.; NAZEERUDDIN, M. K.; GRÄTZEL, M. Fabrication of thin film dye sensitized solar cells with solar to electric power conversion efficiency over $10 \%$. Thin Solid Films, p. 516, v. 4613-4619, 2008.

KALYANASUNDARAM, K.; GRÄTZEL, M. Applications of functionalized transition metal 
complexes in photonic and optoeletronic devices. Coord. Chem. Rev., v. 117, p.347-414, 1998.

KAWANO, R.; MATSUI, H.; MATSUYAMA, C.; SATO, A.; SUSAN, MD. A. B. H.; TANABE, N.; WATANABE, M. High performance dye-sensitized solar cells using ionic liquids as their electrolytes. Journal of photochemistry and photobiology A: Chemistry, v. 164, p. 87-92, 2004.

KAY, A.; GRÄTZEL, M. Low cost photovoltaic modules based on dye sensitized nanocrystalline titanium dioxide and carbon powder. Solar Energy Materials and Solar Cells, v. 44, p. 99-117, 1996.

KONG, J. -M.; CHIA, L. -S.; GOH, N. -K.; CHIA, T. -F.; BROUILLARD, R. Analysis and biological activities of anthocyanins. Phytochemistry, v. 64, p. 923-933, 2003.

LUO, P.; NIU, H.; ZHENG, G.; BAI, X.; ZHANG, M.; WANG, W. From salmon pink to blue natural sensitizers for solar cells: Canna indica L., Salvia splendens, cowberry and Solanum nigrum L. Spectrochimica acta part A: Molecular and Biomolecular Spectroscopy, v. 74, p. 936-942, 2009.

MAURYA, I. C.; SRIVASTAVA, P.; BAHADUR, L. Dye-sensitized solar cell using extract from petals of male flowers Luffa cylindrica $\mathrm{L}$. as a natural sensitizer. Optical Materials, v. 52, p.150-156, 2016.

O'REGAN, B.; GRÄTZEL, M. A low-cost, highefficiency solar cell based on dye-sensitized colloidal films. Nature, v. 353, p. 737-740, 1991.

PATROCINIO, A. O. T.; MIZOGUCHI, S. K.; PATERNO, L. G.; GARCIA, C. G.; IHA, N. Y. M. Efficient and low cost devices for solar energy conversion: efficiency and stability of some naturaldye-sensitized solar cells. Synthetic Metals, v. 159, p. 2342-2344, 2009.

POLO, A. S.; IHA, N. Y. M. Blue sensitizers for solar cells: Natural dyes from Calafate and Jaboticaba. Solar Energy Materials E Solar Cells, v. 90, p. 19361944, 2006.

REVILLA, E.; RYAN, J. M.; MARTIN-ORTEGA, G. Comparison of several procedures used for the extraction of anthocyanins from red grapes. Journal of Agricultural and Food Chemistry, v. 46, p. 45924597, 1998.

TOBIN, L. L.; O’REILLY, T.; ZERULLA, D.; SHERIDAN, J. T. Characterising dye-sensitised solar cells. Optik, 122, 1225-1230, 2011.
YAMAZAKI, E.; MURAYAMA, M.; NISHIKAWA, N.; HASHIMOTO, N.; SHOYAMA, M.; KURITA, O. Utilization of natural carotenoids as photosensitizers for dye-sensitized solar cells. Solar Energy, 81, 512-516, 2007.

ZHANG, D.; LANIER, S. M.; DOWNING, J. A.; AVENT, J. L.; LUM, J.; McHALE, J. L. Betalain pigments for dye-sensitized solar cells. Journal of Photochemistry and Photobiology A: Chemistry, 195, 72-80, 2008.

ZHOU, H.; WU, L.; GAO, Y.; MA, T.; Dye-sensitized solar cells using 20 natural dyes as sensitizers, Journal of Photochemistry and Photobiology A: Chemistry, v. 219, p. 188-194, 2011. 